\title{
Role of Bone Marrow-Derived Monocytes/Macrophages in the Repair of Mucosal Damage Caused by Irradiation and/or Anticancer Drugs in Colitis Model
}

\author{
Junji Takaba, ${ }^{1,2}$ Yuji Mishima, ${ }^{2}$ Kiyohiko Hatake, ${ }^{2}$ and Tadashi Kasahara ${ }^{1}$ \\ ${ }^{1}$ Department of Biochemistry, Graduate School of Pharmaceutical Sciences, Keio University, 1-5-30, Shibakoen, Minato-ku, \\ Tokyo 105-8512, Japan \\ ${ }^{2}$ Department of Clinical Research, Cancer Chemotherapy Center, Japanese Foundation for Cancer Research, 3-10-6 Ariake, \\ Koto-ku, Tokyo 135-0063, Japan \\ Correspondence should be addressed to Tadashi Kasahara, kasahara-td@pha.keio.ac.jp
}

Received 11 September 2010; Revised 18 November 2010; Accepted 7 December 2010

Academic Editor: Magdalena Klink

Copyright (C) 2010 Junji Takaba et al. This is an open access article distributed under the Creative Commons Attribution License, which permits unrestricted use, distribution, and reproduction in any medium, provided the original work is properly cited.

\begin{abstract}
Mucosal damage is a common side effect of many cancer treatments, especially radiotherapy and intensive chemotherapy, which often induce bone marrow (BM) suppression. We observed that acetic acid- (AA-) induced mucosal damage in the colon of mice was worsened by simultaneous treatment with irradiation or 5-FU. However, irradiation 14 days prior to the AA treatment augmented the recovery from mucosal damage, suggesting that the recovery from BM suppression had an advantageous effect on the mucosal repair. In addition, BM transplantation also augmented the recovery from AA-induced mucosal damage. We further confirmed that transplanted BM-derived cells, particularly F4/80+ $\mathrm{Gr}^{+}$"inflammatory" monocytes (Subset 1), accumulated in the damaged mucosal area in the early healing phase, and both of Subset 1 and F4/80 $0^{+} \mathrm{Gr}^{-}$" "resident" monocytes (Subset 2) accumulated in this area in later phases. Our results suggest that monocytes/macrophages contribute to the mucosal recovery and regeneration following mucosal damage by anticancer drug therapy.
\end{abstract}

\section{Introduction}

Mucosal damage is a common side effect of many cancer treatments, especially intensive chemotherapy and radiotherapy. This mucosal damage can seriously affect the quality of life of patients seriously and may sometimes demand changes in or limit the therapy [1-3]. Intestinal mucositis and oral mucositis are significant clinical problems in patients receiving ionizing radiation as the intestinal and oral mucosae are the most radiosensitive organs. Chemotherapyinduced intestinal mucositis involves multiple mechanisms, including induction of crypt cell apoptosis and cytostasis, which implies the possible involvement of pathways relating to p53, the Bcl-2 family, and caspases [3-5]. Further, the nuclear factor-kappa B [6], the cyclooxygenase pathway [7], and epigenetic aberrations [8] have been implicated in the regulation of radiation-induced mucositis. Thus, these findings have lead to further research into the protection and rescue of the intestinal mucosal damages in using the experimental animals. Namely, lysophosphatidic acid [9], Ginkgo biloba extract [10], and D-methionine [11] have been shown to exhibit protective action against radiationinduced organ damage in vitro and in vivo. Recently, histone deacetylase inhibitor [8], lovastatin [12], and ascorbic acid [13] have also been shown to protect against radiationinduced mucositis. Proinflammatory cytokines have also been implicated in the pathophysiology of chemotherapyinduced gastrointestinal mucositis [14]. However, whether these cytokines play a key role in the development and healing of radiotherapy-induced gastrointestinal mucositis remains unknown.

In the present study, we employed an acetic acid- (AA-) induced mucosal damage animal model, an established model for the screening of the anti-inflammatory drugs $[15,16]$, to examine the effects of irradiation or 5 -FU on the healing process following AA-induced mucosal damage. 
Surprisingly, we found that irradiation prior to AA-induced mucosal damage enhanced mucosal healing, while the simultaneous irradiation or 5-FU treatment simultaneously with AA treatment exacerbated the mucosal damage. Since irradiation or anticancer drugs therapy also induces severe leukocytopenia, the effect of bone marrow transplantation (BMT) on mucosal healing was also studied. In particular, we studied the two monocyte/macrophage subsets, "inflammatory" and "resident" [17-21], to determine how these monocyte/macrophage subsets migrate to the mucosal damaged lesion and to elucidate their roles in mucosal healing.

Several reports have shown that monocytes/macrophages contribute to the healing of wounds arising from vascular injury [22], spinal cord injury [23], and myocardial infarction [24]. Still other studies have indicated that monocytes/macrophages may promote wound healing following skin injury [25-28]. However, the role of monocyte/macrophage subsets in the gastrointestinal mucositis has not been elucidated. Here, we propose a role of monocytes/macrophages in the protection against the intestinal mucosal damage.

\section{Materials and Methods}

2.1. Mice and Total Body Irradiation (TBI). C57BL/6J male mice, aged 6 weeks, were purchased from Charles River Japan, Inc. (Yokohama). The mice were maintained under specific pathogen-free conditions and provided with sterile food and water ad libitum. The animals were handled and treated in accordance with the guidelines set forth by the animal use and care committee of the Japanese Foundation for Cancer Research, and all procedures conformed to the NIH guide for the Care and Use of Laboratory Animals. The mice were irradiated totally with a total dose of $4 \mathrm{~Gy}$ per animal using an X-ray generator as a radiation therapy and designated as RT mice. The irradiated mice were bred in a filter-topped cage to prevent infection. The absolute count of white blood cells (WBCs) was analyzed using an F-820 semiautomated hematology analyzer (Sysmex, Kobe, Japan).

2.2. Induction of Experimental Mucosal Damage. Twenty microliters of 3\% AA (Wako, Tokyo, Japan) was injected into the lumen of the colon and retained for $20 \mathrm{~s}$ using roundended tweezers. Thereafter, the lumen was washed with saline and stitched closed as described previously $[9,15,16]$. Prior to or after mucosal damage, mice were administered 5-FU $(100 \mathrm{mg} / \mathrm{kg})(\mathrm{AA}+5-\mathrm{FU})$ i.v. via tail vein or radiation $(4 \mathrm{~Gy})$ (AA + Radiation Therapy (RT)) as indicated. On the day of evaluation, the colon was longitudinally incised and spread open, and the size of the damaged area (length $\times$ width $\left.\left(\mathrm{mm}^{2}\right)\right)$ was determined using a stereoscopic microscope.

2.3. BMT and Cell Labeling. BMCs were flushed from the femur and tibia with RPMI 1640 medium using a $26 \mathrm{G}$ $1 / 2$ needle. To remove debris, the suspension was filtered through a $35 \mu \mathrm{m}$ cell strainer (Falcon). The cells were then washed with medium and counted, and $1 \times 10^{7}$ cells were injected into the tail vein of each of the mucosally damaged mice. To enable tracking analysis, BMCs were stained with
VivoTag 750 (VT750; Ex: $750 \pm 5$ nm, Em: $775 \pm 5$ nm, MW: $980 \mathrm{Da})$ to visualize the accumulation of cells in vivo. VT750 was commercially obtained from VisEn Medical (Woburn, MA; now PerkinElmer Heath Sciences, Inc.). Cells were incubated with $30 \mu \mathrm{g} / \mathrm{ml} \mathrm{VT750} \mathrm{for} 30 \mathrm{~min}$ at $37^{\circ} \mathrm{C}$ and washed twice after labeling. For further analysis, BMCs were stained with $10 \mu \mathrm{M}$ CFDA-SE (Carboxyfluorescein diacetate, succinimidyl ester; Molecular probes; Invitrogen) for $15 \mathrm{~min}$ at $37^{\circ} \mathrm{C}$. The cells were then repelleted by centrifugation, resuspended in fresh, prewarmed medium, and incubated for $30 \mathrm{~min}$ at room temperature to ensure complete incorporation of the probe before a final washing step.

\subsection{Preparation of Damaged Mucosa and Identification of} Injected BMCs. Dissected mucosa was incubated in calcium and magnesium-free HBSS (GIBCO) containing 2.5\% heatinactivated FBS and $1 \mathrm{mM}$ DTT (Sigma-Aldrich) to remove mucus. The mucosa was then incubated in HBSS containing $1 \mathrm{mM}$ EDTA (GIBCO) for $45 \mathrm{~min}$ at $37^{\circ} \mathrm{C}$. Tissues were then collected and incubated in HBSS containing $1 \mathrm{mg} / \mathrm{ml}$ collagenase (Nacalai Tesque, Tokyo, Japan) and $0.1 \mathrm{mg} / \mathrm{ml}$ DNase I for $60 \mathrm{~min}$ at $37^{\circ} \mathrm{C}$, and cells were washed and reacted with an antibody for flow cytometric analysis.

2.5. Flow Cytometric Analysis. The following monoclonal antibodies and staining reagents were used in combination according to the manufacturers' protocols: Phycoerythrin(PE-) conjugated CD11b (BD Pharmingen), Gr1 (Ly6C/G; BD Pharmingen), Peridinin Chlorophyll Protein-Cyanin 5.5(PerCP-Cy5.5-) conjugated anti-CD11b (BD Pharmingen), and allophycocyanin- (APC-) conjugated anti-CD62L (Beckman Coulter), anti-Gr1 (Ly6C/G) (BD Pharmingen), or anti-F4/80 (Caltag). To exclude nonviable cells, 7-aminoactinomycin D (7-AAD) was used. Cells were stored in cold conditions and protected from light; they were analyzed approximately $15 \mathrm{~min}$ after addition of 7-AAD. Thereafter, cells were analyzed on an FACSCalibur flow cytometer (Becton Dickinson, Franklin Lakes, NJ) using CellQuest software (Becton Dickinson).

2.6. Confocal Microscopic Analysis. In vivo monitoring of cell migration was performed using the AA + 5-FU model. On day 0 , the mice were treated with AA and 5-FU $(100 \mathrm{mg} / \mathrm{kg})$, and after $24 \mathrm{~h}, 1 \times 10^{7}$ VT750-labeled BMCs were injected into the mice via the tail vein. On day 2 , the colon was excised from the mice, and the damaged area of the mucosa was longitudinally incised and spread out for laser scanning microscopy (Olympus IV100).

2.7. Statistical Analysis. Data are expressed as mean \pm SE. Data were analyzed using Welch's $t$-test to compare between two groups, Tukey's method was used between three groups, and differences with $P<.05$ were considered statistically significant.

\section{Results}

3.1. TBI-Induced Leukocytopenia and Thrombocytopenia. It is well known that TBI induces mucosal injury to cancer 


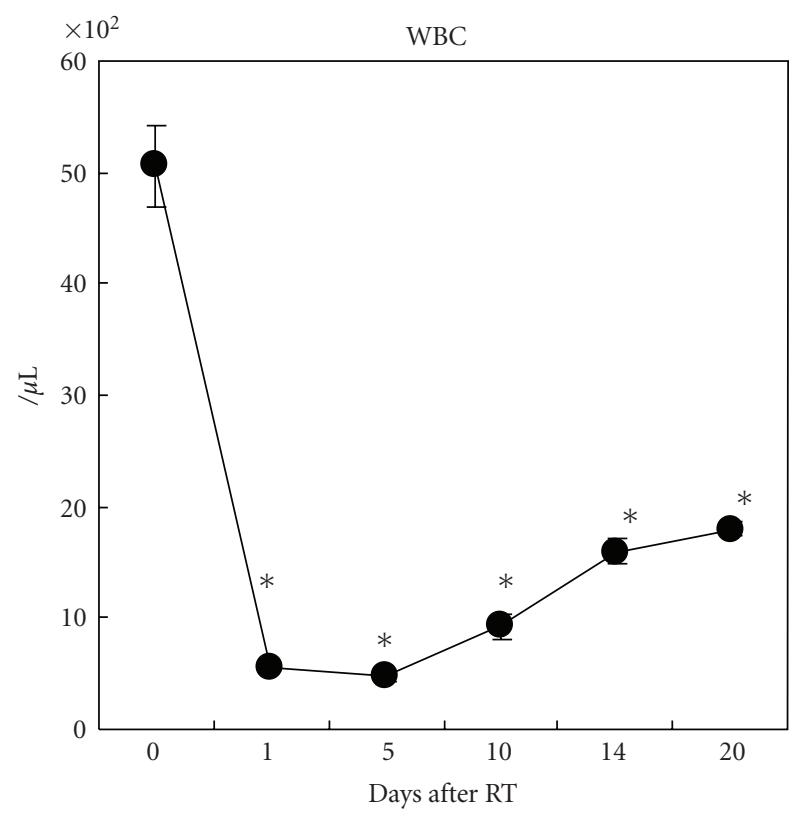

(a)

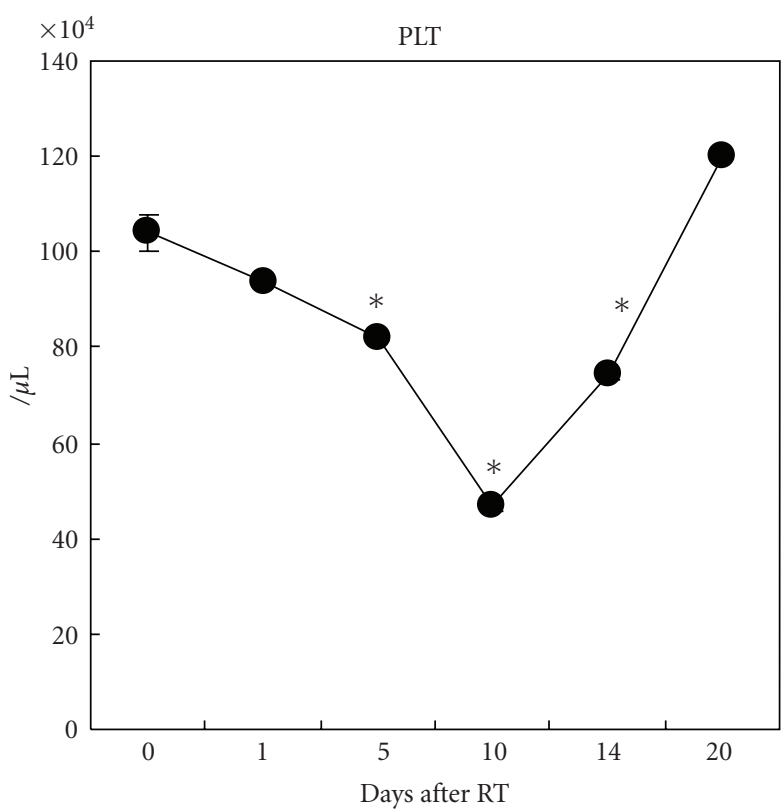

(b)

FIGURE 1: Total body irradiation (TBI) as a radiation therapy (RT) induced leukocytopenia and thrombocytopenia. Twenty-five mice were divided into 5 groups, and each group was irradiated by a dose of $4 \mathrm{~Gy}$ on day 0 . Mice were sacrificed, and white blood cells (WBC) were counted using a semiautomated hematology analyzer F-820 (Sysmex) on day 1, 5, 10, 14, and 20, respectively ( $n=5 /$ each time point). (a) WBC number decreased after TBI, and the low value continued around day 5. (b) Platelets number also decreased, and the lowest number was observed around day 10 . Values represent mean \pm SEM. ${ }^{*} P<.05$ versus day 0 . Data were analyzed using the Tukey method.

patients. In order to mimic similar condition, we chose TBI as a radiotherapy (RT) but not local irradiation. A dose of 4 Gy TBI induced leukocytopenia and thrombocytopenia in mice (Figures 1(a), 1(b)). TBI drastically reduced the WBC count within 1 day; the WBC nadir continued for 1 week and then gradually tended to recover. Similarly, the platelet count decreased; however, the decrease was less severe, with the nadir occurring on day 10 . We therefore assumed that day 14 after TBI represented a favorable stage in the recovery phase for both WBCs and platelets.

3.2. The Relationship between Mucosal Damage and Irradiation. Experimental mucosal damage in the colon was induced by $3 \%$ AA. To evaluate mucosal damage, the colon was removed, longitudinally incised, and spread out. The area of the damaged zone was then measured using a stereoscopic microscope (Figure 2(a)). Concomitantly, we examined the effect of RT on mucosal damage in the colon. When the AA-treated mice were irradiated on day 0 , the area of damage tended to be more widespread than that in nonirradiated mice on day 7 . This indicated that RT delayed the healing of mucosal damage. Although the BMC count did not decrease, the WBC count decreased significantly (Figure 2(b)). In contrast, when mice were irradiated 14 days prior to inducing mucosal damage with AA at day 0 (Pre-RT), we found that the damaged area was significantly decreased on day 7 (AA versus AA + Pre-RT; Figure 2(c)). This observation suggests that preirradiation favored the healing of mucosal damage. During these periods, the
WBC count remained lower in the irradiated mice than in the nonirradiated mice; however, the count suggested recovery, so we chose day 14 as Pre-RT. In addition, some of the monocyte-derived cytokines and chemokines were upregulated during these periods (data not shown).

3.3. Irradiation Affected the Proportional Change of Monocyte Subsets. Since Pre-RT favored the healing of mucosal damage in the colon, we assumed that TBI affected not only the WBC count but also the peripheral blood monocyte subsets. As shown in Figure 3, kinetic changes in peripheral blood monocyte subsets were induced by RT. One monocyte subset, $\mathrm{CD}_{11 \mathrm{~b}}{ }^{+} \mathrm{CD} 62 \mathrm{~L}^{+}$Subset 1, was dominant on day 0 compared with the $\mathrm{CD}_{11 \mathrm{~b}}{ }^{+} \mathrm{CD} 62 \mathrm{~L}^{-}$Subset 2 (76.4\% versus $23.6 \%$ ). After RT, however, the proportion gradually changed, and

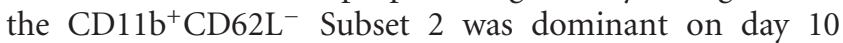
(48.9\% versus $51.1 \%$ ) to day 14 (46.1\% versus 53.9\%), and on day 20 the proportion returned to that observed in the preirradiation state $(72.5 \%$ versus $27.5 \%)$.

In summary, the monocyte subsets changed from Subset 1 dominance to a transient increase in Subset 2 and finally returned to Subset 1 dominance. We speculate that Pre-RT favored the healing of mucosal damage shown in Figure 2(c), which may be associated with the monocyte subset changes reported herein.

3.4. 5-FU Treatment Delayed the Healing of Mucosal Damage. We next examined whether the administration of an anticancer drug would induce the same phenomenon as 


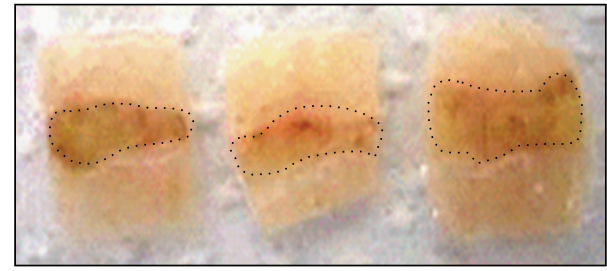

(a)
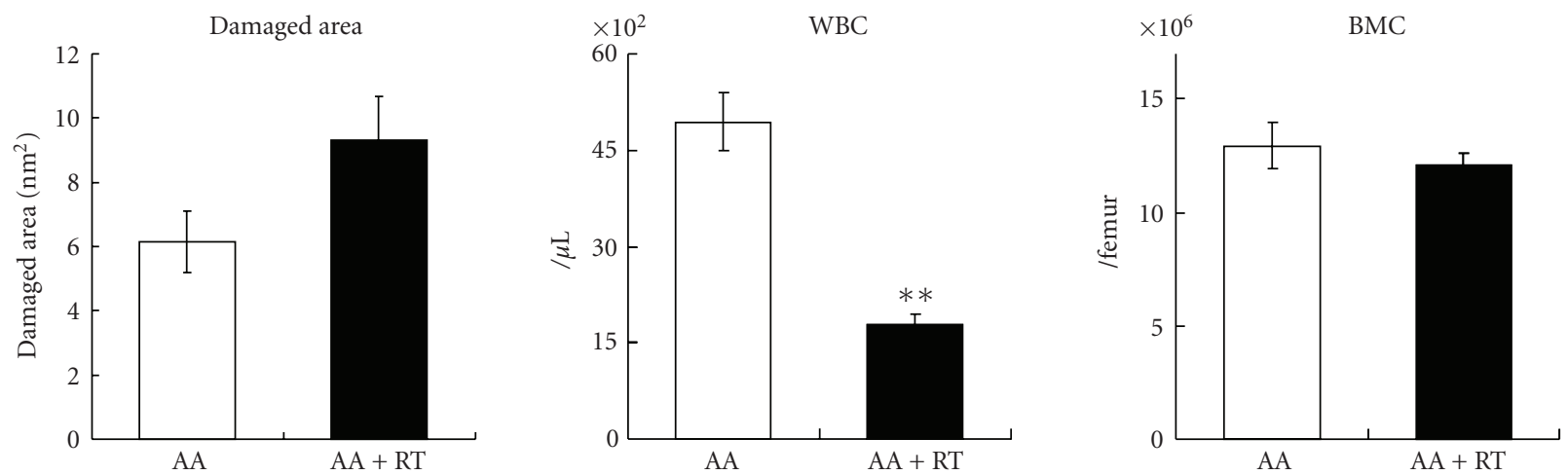

(b)
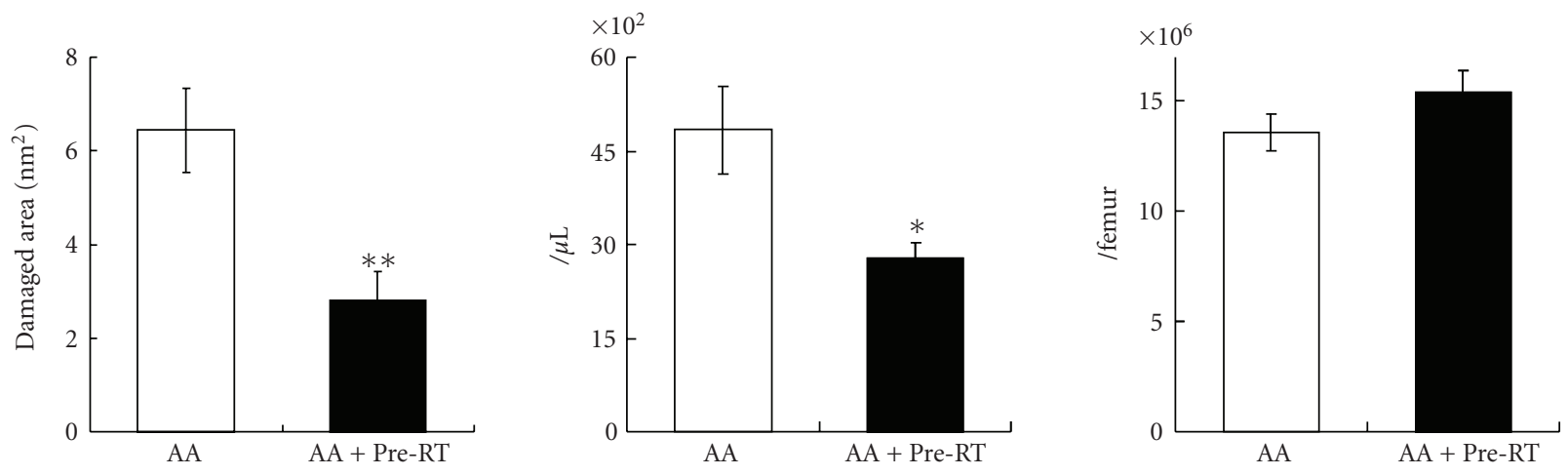

(c)

Figure 2: Effect of pre- or simultaneous irradiation on the acetic acid (AA-) induced mucosal damage. (a) Mucosal damage in the colon induced by $3 \%$ AA. On the evaluated day, colon was longitudinally incised and spread. Damaged area was evaluated with stereoscopic microscope. (b) Mice were induced mucosal damage on day 0 (AA) and irradiated on the same day (AA + RT). WBC and bone marrow cells $(\mathrm{BMC})$ on day 7 were indicated in the right panels. (c) Mice were AA treated (AA) or irradiated 14 days before AA treatment (AA + Pre-RT). Note that the damaged area (AA + Pre-RT) was smaller than nonirradiated control (AA), indicating that preirradiation enhanced healing of mucosal damage. WBC and BMC on day 7 were indicated in the right panels. Values represent mean \pm SEM. ${ }^{*} P<.05,{ }^{* *} P<.01$. Data were analyzed using Welch's $t$-test.

was observed with RT. Administration of 5-FU (100 mg/kg) induced leukocytopenia and BM suppression on day 7 (Figure 4(a)). When 5-FU was administered to AA-treated mice on day 0 , the damaged area increased significantly compared with that in saline-administered control mice on day 7 (Figure 4(b)); that is, 5-FU treatment delayed the healing of mucosal damage, as seen with RT. Furthermore, the delay in the healing of mucosal damage following 5FU treatment was more severe than that with RT. We next determined the effect of BMT on the exacerbation of mucosal damage by 5 -FU treatment.
3.5. Administration of BMCs Enhanced the Healing of Mucosal Damage. Since the BMC count was decreased by 5-FU treatment, we assumed that BMT would help heal the mucosal damage. Mice with AA-induced mucosal damage that were administrated 5-FU (AA + 5-FU) underwent BMT, and we found that BMT with $1 \times 10^{7}$ BMCs showed a significantly enhanced healing of mucosal damage 6 days after BMT (>60\%; Figure 5(a)). AA + 5-FU administration caused significant body weight loss compared with the sham operation (saline-treated) group, but BMT rescued the body weight loss significantly after day 3 (versus AA +5 -FU group) 


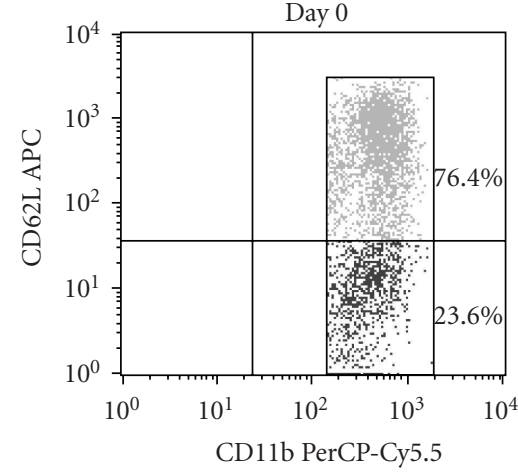

(a)

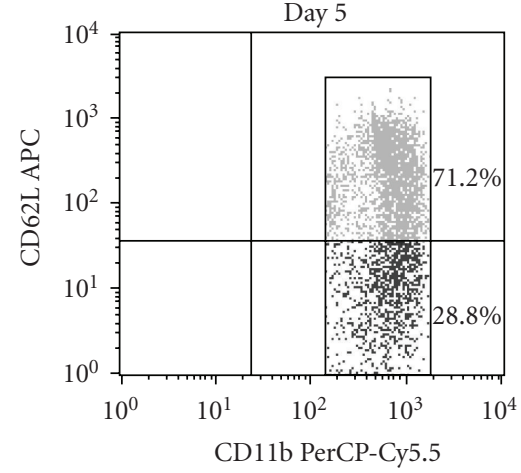

(b)

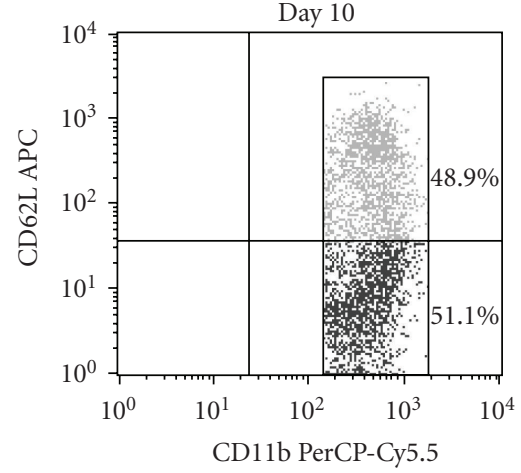

(c)

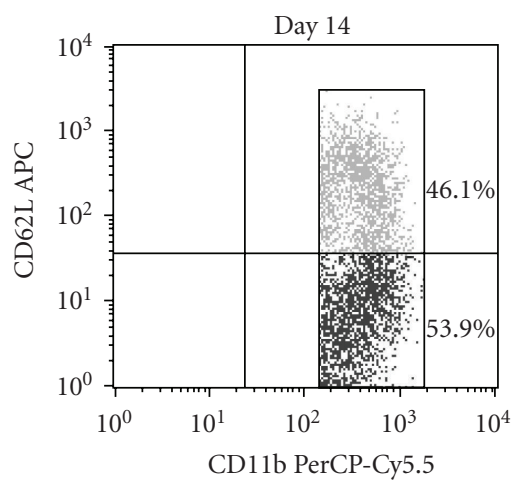

(d)

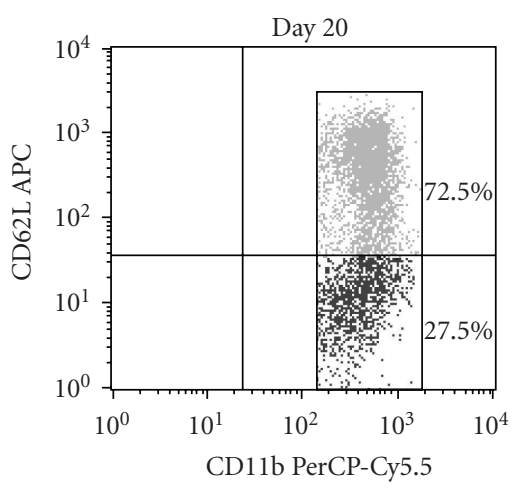

(e)

FIGURE 3: Flow cytometric analysis of peripheral blood monocyte subsets. Five mice were sacrificed at each time point after RT, and whole peripheral blood was pooled. Peripheral blood mononuclear cells (PBMC) were isolated from whole blood using gradient centrifugation method. $1 \times 10^{6}$ PBMC were stained using two antibodies, CD11b-PerCP-Cy5.5 and CD62L-APC. CD11b ${ }^{+}$CD62L $^{+}$population was designated as Subset 1, and CD11 $b^{+} \mathrm{CD} 62 \mathrm{~L}^{-}$population was Subset 2.

(Figure 5(b)). Heavy bleeding in the stool was observed after the operation, particularly in the $\mathrm{AA}+5-\mathrm{FU}$ group.

3.6. Labeled BMCs Migrated into the Damaged Area of the Mucosa. We hypothesized that transplanted BMCs migrate into the damaged area of the mucosa and enhance its healing. To test this hypothesis, we injected Vivotag750labeled BMCs into AA + 5-FU mice and determined whether the labeled cells could be detected in the damaged area using fluorescence microscopy. As shown in Figure 6, labeled BMCs $\left(1 \times 10^{7}\right)$ were markedly accumulated in the damaged area compared with those in the undamaged areas of the mucosa. Thus, it is possible that the labeled BMCs were involved in the healing of the damaged mucosa.

3.7. F4/80+ $\mathrm{GrI}^{+}$(Subset 1) Cells Accumulated in the Damaged Area of the Mucosa in the Early Phase of Healing. To further determine the characteristics of the accumulated cells, we used a CFDA-SE labeling method for flow cytometric analysis (FACS). Single cells accumulated in the damaged tissues were isolated and analyzed by FACS. The isolated cells were identified based on 1 of 3 colors. They were stained with 7-AAD, F4/80-APC, and C11b-PE or 7-AAD, F4/80-APC, and Gr1-PE. The CFDA-positive fraction originated from the transplanted BMC (Figure 7(a)), which clearly expressed CD11b and F4/80 (Figure 7(b)). However, it should be noted that the F4/80+ fraction also expressed Gr1 (Figure 7(c)).

Thus, these analyses identified the accumulated cells in the damaged area as $\mathrm{F} 4 / 80^{+} \mathrm{Gr}^{+}$(Subset 1) monocytes, which exhibited typical monocyte/macrophage morphology (Figure 7(d)).

3.8. Both $\mathrm{F} 4 / 80^{+} \mathrm{GrI}^{+}$(Subset 1) and F4/80 $\mathrm{Gr}^{-}$(Subset 2) Cells Accumulated in the Damaged Area of the Mucosa in the Later Phase of Healing. Labeled BMCs $\left(1 \times 10^{7}\right.$ cells) transplanted into $\mathrm{AA}+5$-FU mice were monitored for 24,72 , and $120 \mathrm{~h}$ by FACS. F4/80 $\mathrm{Gr}^{+}$(Subset 1) monocytes accumulated in the damaged area of the mucosa $24 \mathrm{~h}$ after BMT. However, Gr1 expression was weakened $72 \mathrm{~h}$ after BMT $(86.7 \%)$ and was further weakened at $120 \mathrm{~h}$ after BMT $(51.3 \%)$ compared with the expression at $24 \mathrm{~h}$ (98.8\%), (Figure 8). We therefore assumed that F4/80 ${ }^{+} \mathrm{Gr}^{+}$ (Subset 1) monocytes migrated to the damaged area of the mucosa predominantly in the early stages of healing, while $\mathrm{F} 4 / 80^{+} \mathrm{Gr}^{-}$(Subset 2) monocytes accumulated in the area during the later phase. 

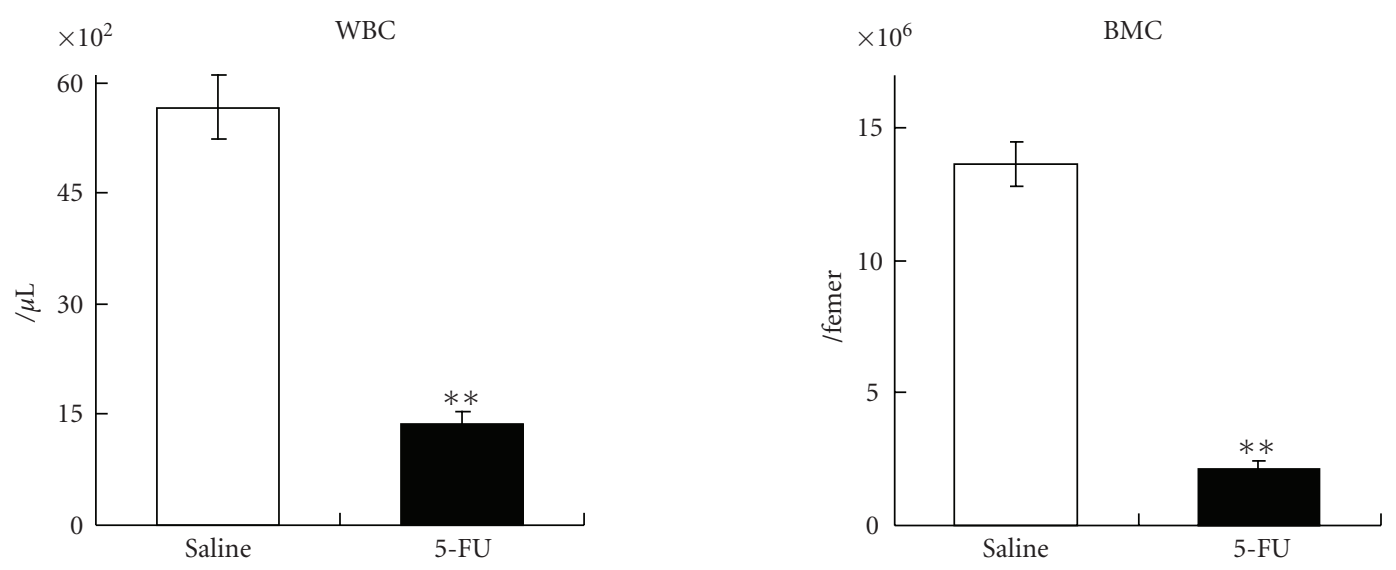

(a)

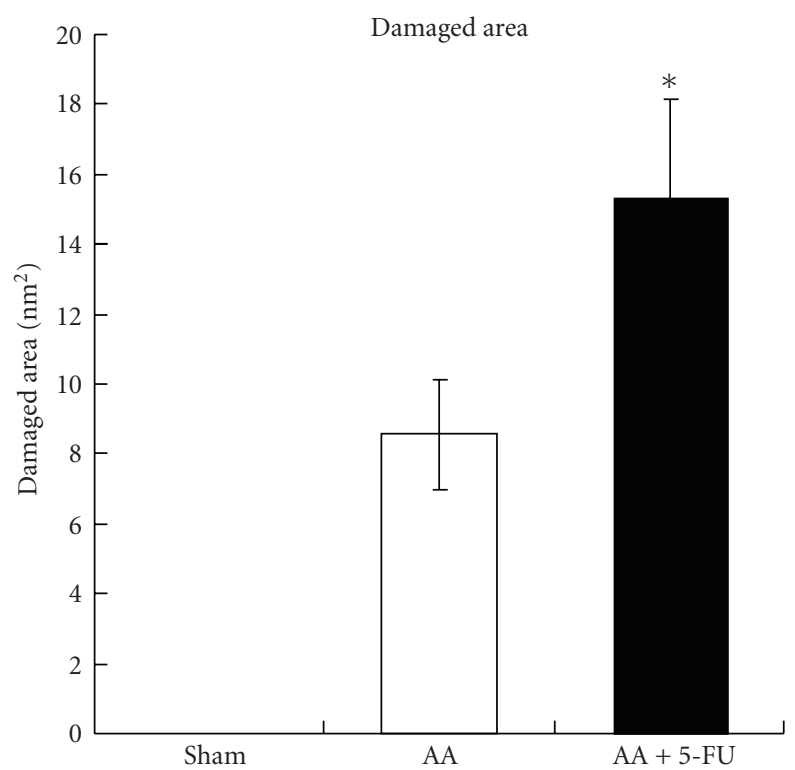

(b)

FIGURE 4: Effect of 5-FU treatment on the AA-induced mucosal damage. (a) 5-FU induced leukocytopenia and bone marrow suppression on day 7. Values represent mean \pm SEM. Data were analyzed using the Welch's $t$-test. ${ }^{* *} P<.01$, Saline versus 5 -FU. (b) Mucosal damage was induced by AA treatment on day 0 and injected 5 -FU $(100 \mathrm{mg} / \mathrm{kg})$ on the same day. 5 -FU treatment exacerbated the mucosal damage and delayed mucosal healing on day 7 like the simultaneous irradiation in Figure 2(b). Values represent mean \pm SEM. Data were analyzed using the Tukey method. $* P<.05$, AA versus AA +5 -FU.

\section{Discussion}

Since RT or anticancer drug administration induces not only leukocytopenia but also BM suppression, we hypothesized that these treatments might delay the healing from mucosal damage. We surprisingly found that preirradiation accelerated the healing of mucosal damage in mice that were irradiated before the colon was damaged by AA treatment. We also found that BMT significantly enhanced the healing of mucosal damage induced by $\mathrm{AA}+5$-FU treatment. These observations strongly suggested that BMCs or a BMCderived cell population contributed to mucosal regeneration following damage. We thus determined the cell type accumulated in the mucosal lesion and investigated which monocytes or monocyte subset played a critical role in the healing of mucosal damage caused by irradiation or chemotherapy.

As mentioned before, mucosal damage is a common side effect of many cancer treatments, and unfortunately there is no therapy for this disorder as yet [1-3]. Intestinal and oral mucositis are significant clinical problems in patients receiving irradiation as the intestinal and oral mucosae are the most radiosensitive organs. It was difficult to establish the mucosal injury model using irradiation or anticancer drug alone. So, we combined AA with TBI or with 5-FU 


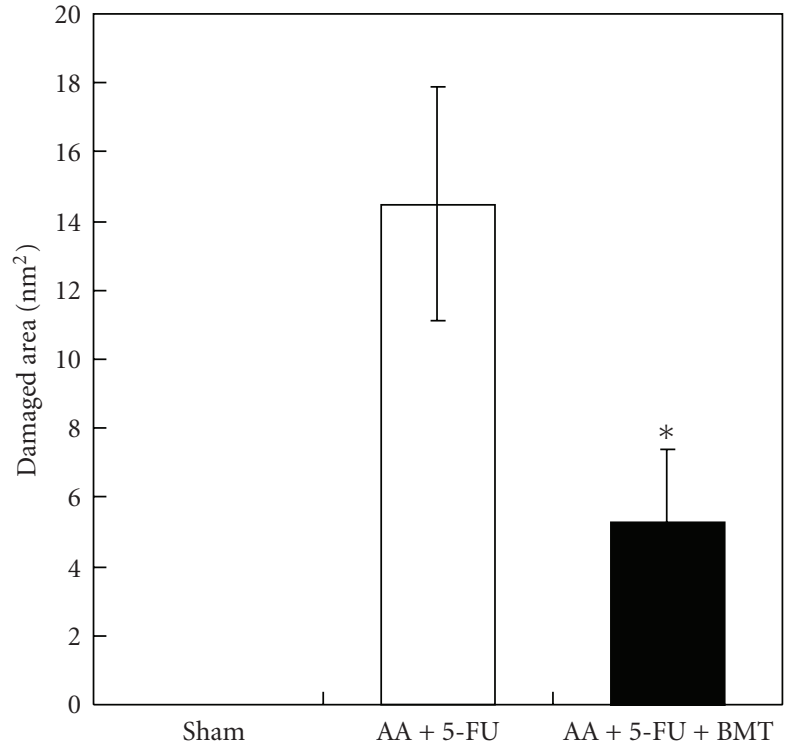

(a)

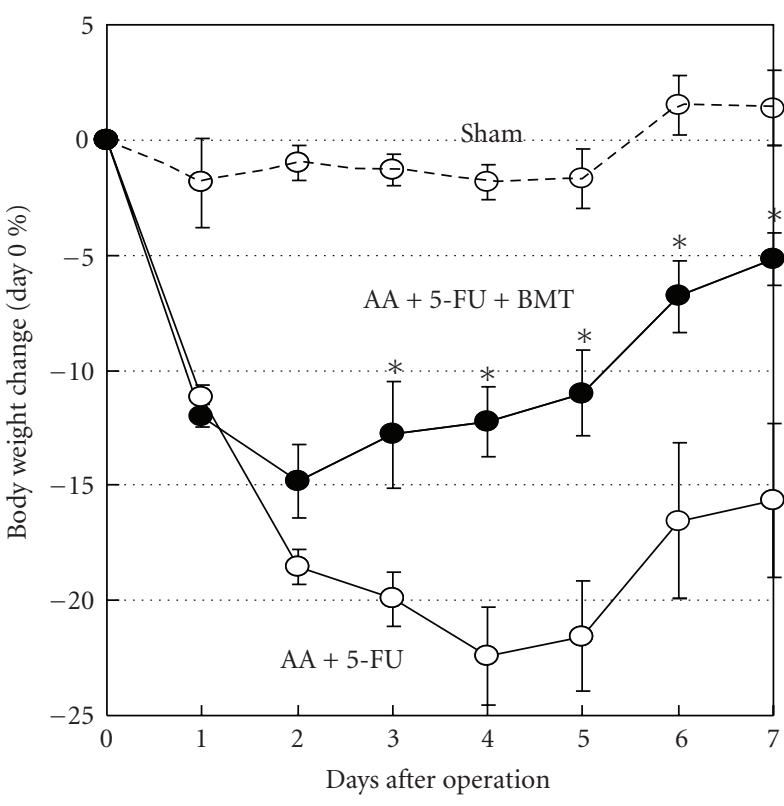

(b)

FIGURE 5: Administration of bone marrow cells (BMC) enhanced healing mucosal damage. (a) Mucosal damage was induced by the AA treatment and the additional administration of 5 -FU $(100 \mathrm{mg} / \mathrm{kg})$ on day $0\left(\mathrm{AA}+5\right.$-FU). $1 \times 10^{7} \mathrm{BMC}$ were injected into AA +5 -FU mice on day 1. In the Sham-operated group (control), saline was injected into colon instead of AA. Administration of BMC enhanced healing mucosal damage in AA + 5-FU mice on day 7 significantly. (b) Comparison of changes in body weight between each group. Although AA + 5 -FU mice significantly reduce their body weight, BMT rescued the body weight loss from day 3 . Values represent mean \pm SEM. Data were analyzed using the Tukey method. ${ }^{*} P<.05$, AA +5 -FU versus AA +5 -FU + BMT.

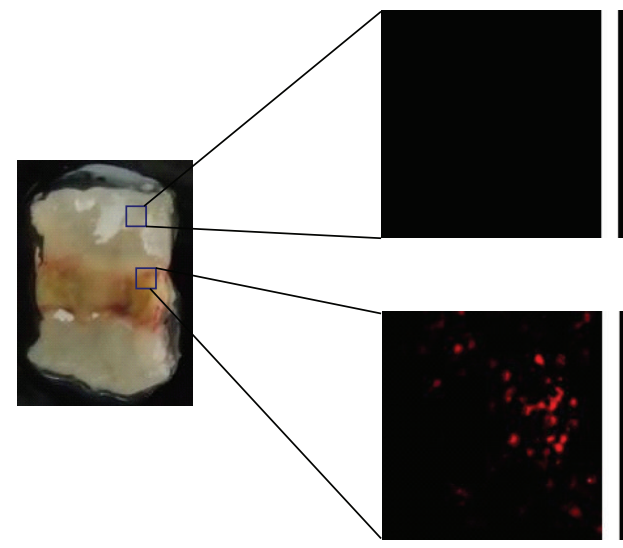

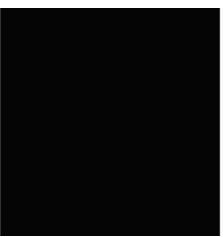

(a)
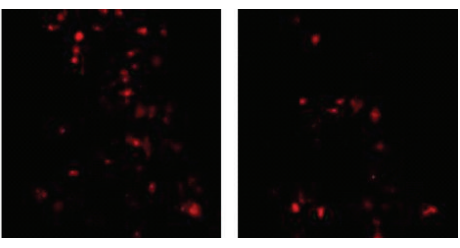

(b)

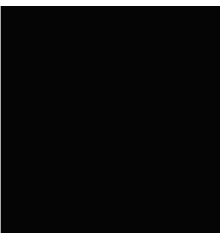

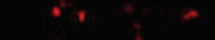

Figure 6: Transplanted BMC migrated into mucosal damaged area. $1 \times 10^{7}$ BMC were labeled using Vivotag750. These cells were transplanted into AA + 5-FU model via tail vein. After 24 hours, mice were sacrificed, and the colon was observed. The labeled cells could be detected in mucosal damaged area by fluorescence microscope. Transplanted BMC accumulated significantly in mucosal damaged area (b), but not in normal area (a). Three pictures were $z$-axis high, middle, and low in one of the particular area.

to mimic mucosal injury in the cancer patients. We also tried DSS (Dextran sodium sulfate) model, but it was more complicated because DSS has the anticoagulate effect by itself and far from the clinical context of cancer patient. Although the AA-induced mucosal injury model is an old type, it has widely been used for evaluating drug efficacy.

The mechanism of radiation- or chemotherapy-induced mucositis has been extensively documented [5-7] and has enabled testing of various treatment modalities in experimental animals [8-13]. Repair of tissue damage is an interactive process that involves soluble mediators, extracellular matrix components, resident cells, and infiltrating leukocytes $[28,29]$. Initially, neutrophils accumulate at wound sites, which is followed by a large influx of macrophages and a small number of $\mathrm{T}$ lymphocytes. In the proliferative phase, massive angiogenesis occurs, and fibroblasts migrate into 


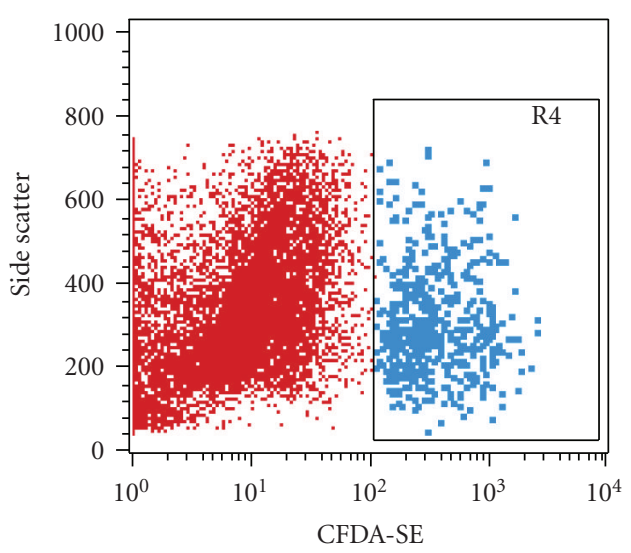

(a)

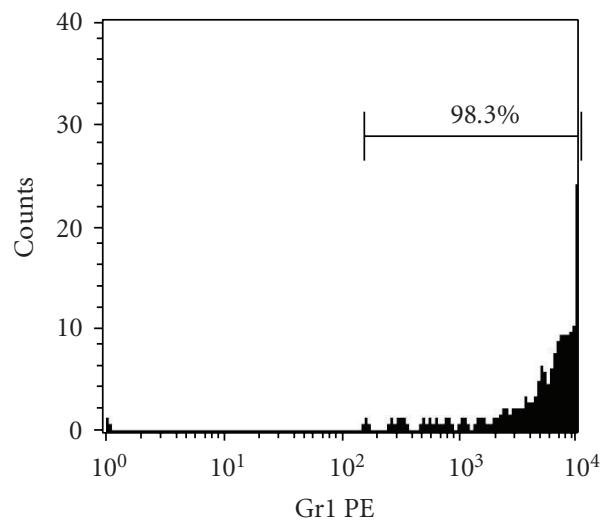

(c)

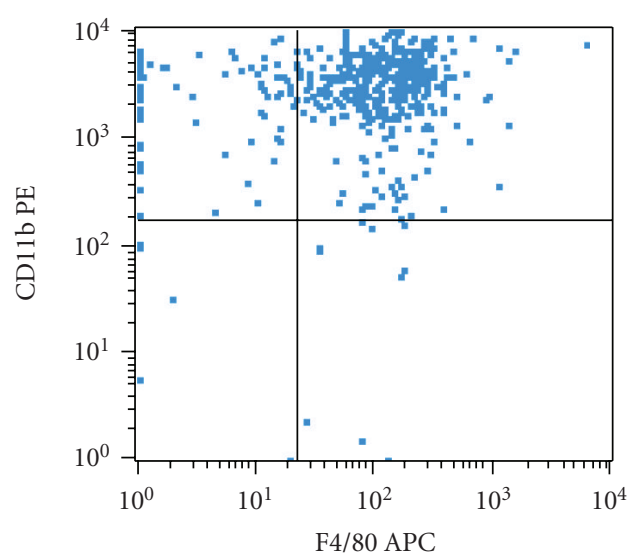

(b)

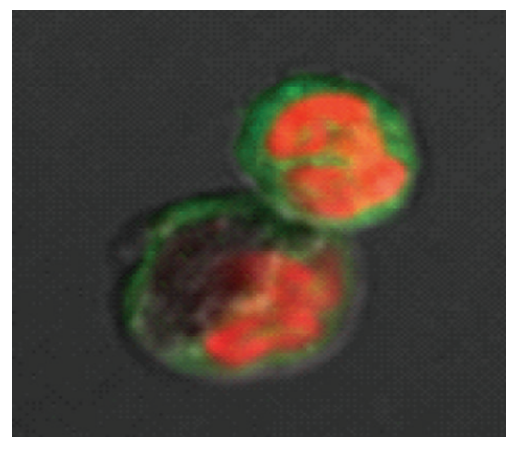

(d)

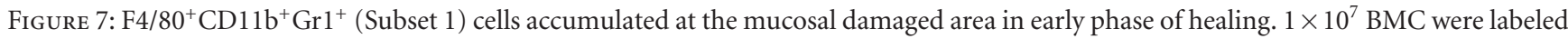
using CFDA-SE. These cells were injected into AA + 5-FU mice via tail vein. After 24 hours, colon was dissected and incubated in calcium and magnesium-free HBSS containing 2.5\% heat-inactivated FBS and $1 \mathrm{mM}$ DTT to remove mucus. After the tissues were treated with collagenase and DNase I for $60 \mathrm{~min}$ at $37^{\circ} \mathrm{C}$, cells were washed and stained with 7-AAD, F4/80-APC, and C11b-PE or 7-AAD, F4/80-APC, and Gr1-PE, for the flow cytometric analysis. 7-AAD was used for exclusion of dead cells. (a) CFDA-SE positive cells indicated bone marrowderived cells. (b) CFDA-SE positive population was $\mathrm{CD} 11 \mathrm{~b}^{+} \mathrm{F} 4 / 80^{+}$monocytes. (c) $\mathrm{F} 4 / 80$ positive population was almost all Gr $1^{+}$cells, indicating the F4/80+ $\mathrm{Gr}^{+}$Subset 1 monocytes. (d) The population had typical monocytes morphology.

the wound, proliferate, and transform into myofibroblasts, which play a major role in the formation of granulation tissue. Recently, Ishida et al. using $\mathrm{CXC}_{3} \mathrm{R} 1$ - (CXC chemokine receptor 1-) knockout mice demonstrated that recruitment of $\mathrm{CXC}_{3} \mathrm{R} 1$-positive monocytes/macrophages is critical for skin wound healing [28].

Fluorescence resulting from illumination with an Argon $488 \mathrm{~nm}$, DPSS $561 \mathrm{~nm}$, or HeNe $633 \mathrm{~nm}$ laser is difficult to detect during in vivo imaging of the large intestine since mice on a normal diet exhibit autofluorescence; it is thus also difficult to image the contents of the colon and feces. Although the autofluorescence can be reduced with a purified diet, it does not completely disappear (data not shown). Therefore, we used the following 2 methods to detect the labeled transplanted cells. One was VT750 staining for fluorescence microscopy, and the other was CFDA-SE for FACS analysis. A $748 \mathrm{~nm}$ LD (laser diode) prevented autofluorescence due to diet, and in our analysis, cells and tissues in the colon could not be detected by
FACS. We thus demonstrated that $\mathrm{F} 4 / 80^{+} \mathrm{Gr}^{+}$(Subset 1) monocytes/macrophages were recruited to the damaged area of the mucosa during the early phase of healing. Both $\mathrm{F} 4 / 80^{+} \mathrm{Gr}^{+}$(Subset 1) and $\mathrm{F} 4 / 80^{+} \mathrm{Gr}^{-}$(Subset 2) monocytes/macrophages accumulated in the damaged area in the later phase of the healing process. Ishida et al. [28] reported that both $\mathrm{CX}_{3} \mathrm{CR} 1^{+} \mathrm{CCR} 2^{-}$(Subset 1) and $\mathrm{CX}_{3} \mathrm{CR}^{+}{ }^{+} \mathrm{CCR}_{2}{ }^{+}$(Subset 2) monocytes/macrophages accumulated in skin wound sites in the late phase of healing and that these cells contributed to wound healing. Our results indicated that $\mathrm{F} 4 / 80^{+} \mathrm{Gr}^{+}$and $\mathrm{F} 4 / 80^{+} \mathrm{Gr} 1^{-}$ monocytes/macrophages are sequentially recruited to damaged areas of the mucosa in 2 distinct phases. Subset $1 \mathrm{can}$ be designated as immature monocytes/macrophages and Subset 2 as mature monocytes/macrophages. Since Subset 1 cells could possibly be classified as Subset 2 [18] cells given the continuum of development, some proportion of Subset 1 monocytes/macrophages may differentiate into Subset 2 monocytes/macrophages in the late phase of healing 


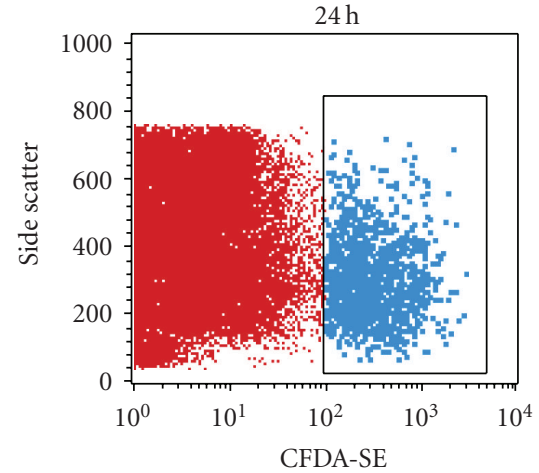

(a)

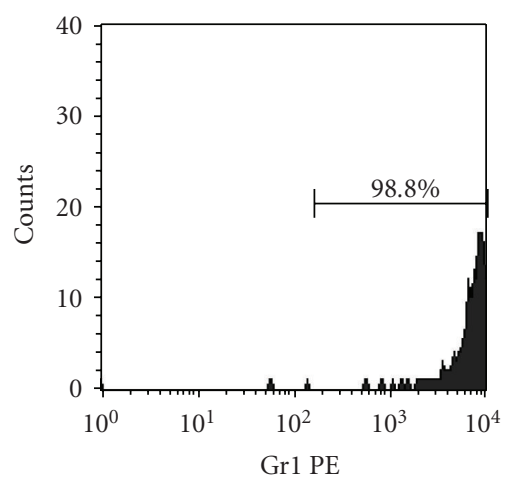

(d)

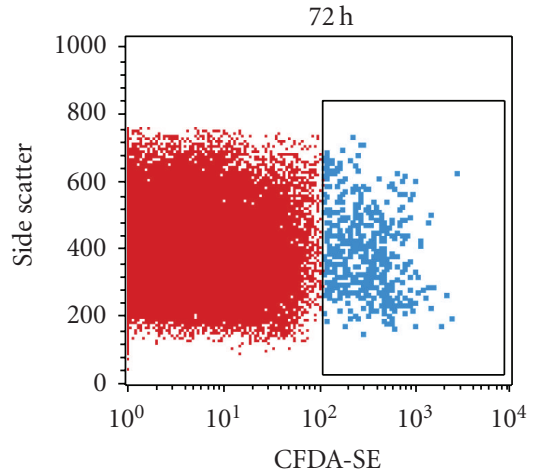

(b)

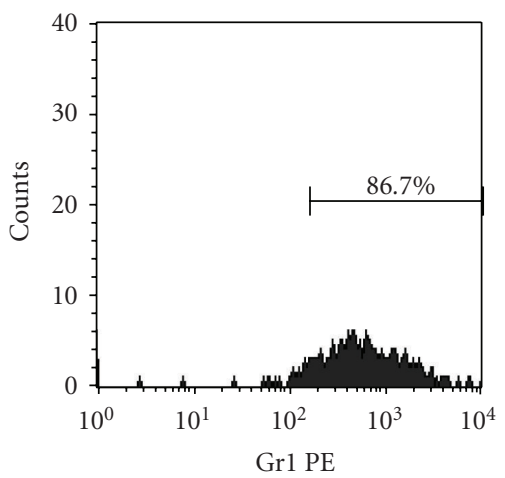

(e)

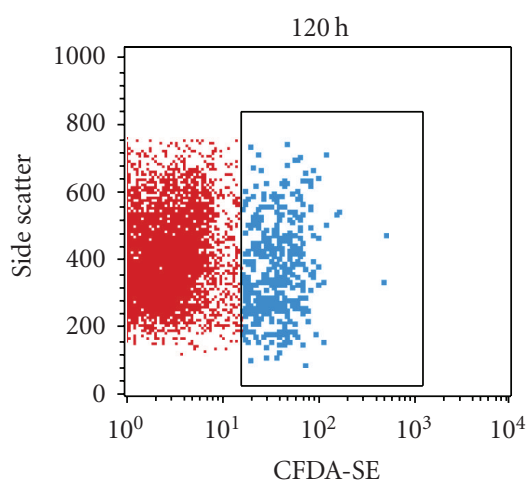

(c)

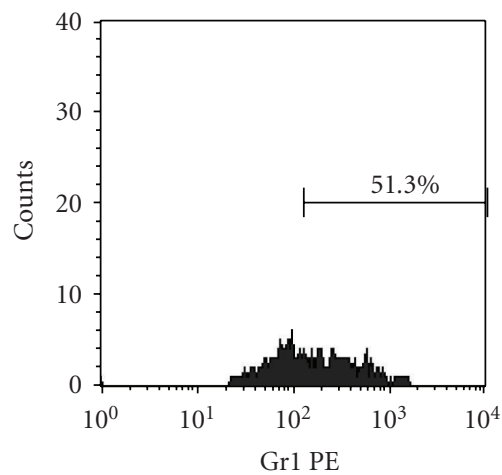

(f)

Figure 8: Both of F4/80+ $\mathrm{Gr}^{+}$(Subset 1) and $\mathrm{F} 4 / 80^{+} \mathrm{Gr}^{-}$(Subset 2) cells accumulated mucosal damaged area in late phase. Accumulated cells at the mucosal damaged area in late phase were analyzed at three time points after BMT. At 24 hours after BMT, almost all accumulating cells were $\mathrm{F} 4 / 80^{+} \mathrm{Gr}^{+}$Subset 1 monocytes (98.8\%), and these $\mathrm{Gr} 1^{+}$Subset 1 monocytes decreased to $86.7 \%$ after 72 hours and $51.3 \%$ after 120 hours.

$[18,30,31]$. One study also demonstrated that monocytes have properties similar to those of pluripotent stem cells [32], so a particular population of monocytes may also differentiate into mucosal cells.

Irradiation also induced upregulation of serum cytokines, including that of G-CSF and M-CSF (data not shown). G-CSF has been shown to have a clinically beneficial role in healing. Two randomized clinical studies showed that G-CSF was effective in reducing the incidence of oral mucositis caused by chemotherapy [33, 34] and also effectively helped reduce the severity of mucositis [35]. However, several studies on G-CSF and oral mucositis have also reported conflicting results. A randomized, controlled study using a prophylactic GM-CSF mouthwash $[36,37]$ and another randomized, controlled trial using a GM-CSF mouthwash as treatment for oral mucositis in hematopoietic stem cell transplantation patients showed no positive effects [38]. Although still controversial, topical administration of GM-CSF appears to have some beneficial effects on oral mucosal damage, its duration, and severity $[39,40]$.

Monocytes, a complex leukocyte population that expresses a range of chemokine receptors, are generated in $\mathrm{BM}$ and then released into circulation [17]. Mouse monocytes are classified according to their expression of CCR2, CD62L (L-selectin), Gr1, and $\mathrm{CX}_{3} \mathrm{CR} 1$ [17, 18].
To functionally distinguish two mouse monocyte subsets, Geissman et al. [17] adoptively transferred $\mathrm{GFP}^{+}$monocytes from $\mathrm{CX}_{3} \mathrm{CR} 1 \mathrm{GFP} /{ }^{+}$mice to naive and immunologically challenged mice and studied $\mathrm{GFP}^{+}$monocyte cell fate and function. They found that one monocyte subset expressed CCR2, CD62L, Gr1, and only moderate amounts of $\mathrm{CX}_{3} \mathrm{CR} 1$, while the other subset did not express CCR2 or CD62L but expressed higher amounts of $\mathrm{CX}_{3} \mathrm{CR} 1$. The monocyte subset expressing $\mathrm{CCR} 2^{+}, \mathrm{CD}_{62} \mathrm{~L}^{+}, \mathrm{Gr}^{+}$, and $\mathrm{CX}_{3} \mathrm{CR} 1^{\text {low }}$ was designated the "inflammatory" subset (Subset 1). This subset was rapidly recruited to the sites of experimentally induced inflammation, but was short-lived after adoptive transfer, and became difficult to detect in the tissues of naive recipients $[17,19-21]$. On the other hand, the CCR2 ${ }^{-}$, $\mathrm{CX}_{3} \mathrm{CR}_{1} 1^{\text {high }}$ monocyte population was found to persist longer in mice after adoptive transfer, and this population was detected in the blood, spleen, lungs, liver, and brain of recipients for several days after transfer. This population was proposed to constitute "resident" monocytes (Subset 2) that are recruited to tissues independently of inflammatory stimuli; these cells were also assumed to differentiate into other populations. Recently, increasing evidence has demonstrated that monocytes/macrophages may contribute to wound healing following vascular injury [22], spinal cord injury [23], and myocardial infarction [24]. Still other studies have 
provided supporting evidence that monocytes/macrophages may promote wound healing after skin injury [25-28]. The relationship between monocyte/macrophage subsets and gastrointestinal mucositis has remained unknown to date. However, in the present study, we revealed a role played by accumulating monocytes in AA-induced gastrointestinal mucositis. In summary, using an animal model, we showed that BM-derived cells, particularly monocytes/macrophages, contribute to regeneration after mucosal damage.

\section{Conclusion}

Acetic acid- (AA-) induced mucosal damage of mouse colon was worsened by simultaneous treatment with irradiation or 5-FU. However, irradiation 14 days prior to AA treatment or BMT augmented recovery from the mucosal damage. We confirmed that $\mathrm{F} 4 / 80^{+} \mathrm{Gr} 1^{+}$"inflammatory" monocytes accumulated in the damaged area of the mucosa in the early phase of healing. This study suggests that monocytes/macrophages contribute to recovery and regeneration following mucosal damage.

\section{Conflict of Interests}

The authors declare no financial or commercial conflicts of interests.

$\begin{array}{ll}\text { Abbreviations } \\ \text { AA: } & \text { acetic acid } \\ \text { BMT: } & \text { bone marrow transplantation } \\ \text { TBI: } & \text { total body irradiation } \\ \text { RT: } & \text { radiotherapy } \\ \text { BMCs: } & \text { Bone marrow cells } \\ \text { PE: } & \text { Phycoerythrin } \\ \text { PerCP: } & \text { Peridinin Chlorophyll Protein-Cyanin } \\ \text { APC: } & \text { allophycocyanin } \\ \text { CFDA-SE: } & \text { Carboxyfluorescein diacetate-succinimidyl ester } \\ \text { CXCR: } & \text { CXC chemokine receptor } \\ \text { CCR: } & \text { CC chemokine receptor } \\ \text { WBCs: } & \text { White blood cells. }\end{array}$

\section{Acknowledgments}

The authors thank Dr. H. Ishiyama, K. Ohta, S. Nakazato, and N. Kodama for their technical assistance. This work was funded partly by a grant-in-aid (21590072) from the Ministry of Education, Science, Culture and Sports in Japan and partly by Otsuka Pharmaceutical Co., Ltd, Tokyo, Japan.

\section{References}

[1] S. T. Sonis, "Regimen-related gastrointestinal toxicities in cancer patients," Current Opinion in Supportive and Palliative Care, vol. 4, no. 1, pp. 26-30, 2010.

[2] S. T. Sonis, L. S. Elting, D. Keefe et al., "Perspectives on cancer therapy-induced mucosal injury: pathogenesis, measurement, epidemiology, and consequences for patients," Cancer, vol. 100, no. 9, pp. 1995-2025, 2004.
[3] J. M. Bowen, R. J. Gibson, A. G. Cummins, and D. M. K. Keefe, "Intestinal mucositis: the role of the Bcl-2 family, p53 and caspases in chemotherapy-induced damage," Supportive Care in Cancer, vol. 14, no. 7, pp. 713-731, 2006.

[4] T. Arai, Y. Kida, B. V. Harmon, and G. C. Gobé, "Comparative alterations in p53 expression and apoptosis in the irradiated rat small and large intestine," British Journal of Cancer, vol. 74, no. 3, pp. 406-412, 1996.

[5] K. Inagaki-Ohara, N. Takamura, S. Yada et al., "Radiationinduced crypt intestinal epithelial cell apoptosis in vivo involves both caspase-3-dependent and -independent pathways," Digestive Diseases and Sciences, vol. 47, no. 12, pp. $2823-$ 2830, 2002.

[6] S. T. Sonis, "The biologic role for nuclear factor-kappaB in disease and its potential involvement in mucosal injury associated with anti-neoplastic therapy," Critical Reviews in Oral Biology and Medicine, vol. 13, no. 5, pp. 380-389, 2002.

[7] R. V. Lalla, C. C. Pilbeam, S. J. Walsh, S. T. Sonis, D. M.K. Keefe, and D. E. Peterson, "Role of the cyclooxygenase pathway in chemotherapy-induced oral mucositis: a pilot study," Supportive Care in Cancer, vol. 18, no. 1, pp. 95-103, 2010.

[8] Y. L. Chung, M. Y. Lee, and N. N. M. Pui, "Epigenetic therapy using the histone deacetylase inhibitor for increasing therapeutic gain in oral cancer: prevention of radiationinduced oral mucositis and inhibition of chemical-induced oral carcinogenesis," Carcinogenesis, vol. 30, no. 8, pp. 13871397, 2009.

[9] W. Deng, L. Balazs, D. Wang, L. Van Middlesworth, G. Tigyi, and L. R. Johnson, "Lysophosphatidic acid protects and rescues intestinal epithelial cells from radiation- and chemotherapy-induced apoptosis," Gastroenterology, vol. 123, no. 1, pp. 206-216, 2002.

[10] G. Şener, L. Kabasakal, B. M. Atasoy et al., "Ginkgo biloba extract protects against ionizing radiation-induced oxidative organ damage in rats," Pharmacological Research, vol. 53, no. 3, pp. 241-252, 2006.

[11] S. B. Vuyyuri, D. A. Hamstra, D. Khanna et al., "Evaluation of D-methionine as a novel oral radiation protector for prevention of mucositis," Clinical Cancer Research, vol. 14, no. 7, pp. 2161-2170, 2008.

[12] C. Ostrau, J. Hülsenbeck, M. Herzog et al., "Lovastatin attenuates ionizing radiation-induced normal tissue damage in vivo," Radiotherapy and Oncology, vol. 92, no. 3, pp. 492499, 2009.

[13] T. Yamamoto, M. Kinoshita, N. Shinomiya et al., "Pretreatment with ascorbic acid prevents lethal gastrointestinal syndrome in mice receiving a massive amount of radiation," Journal of Radiation Research, vol. 51, no. 2, pp. 145-156, 2010.

[14] Z. Y. Ong, R. J. Gibson, J. M. Bowen et al., "Pro-inflammatory cytokines play a key role in the development of radiotherapyinduced gastrointestinal mucositis," Radiation Oncology, vol. 5, p. 22, 2010.

[15] P. Sharon and W. F. Stenson, "Metabolism of arachidonic acid in acetic acid colitis in rats. Similarity to human inflammatory bowel disease," Gastroenterology, vol. 88, no. 1, pp. 55-63, 1985.

[16] L. R. Fitzpatrick, J. S. Bostwick, M. Renzetti, R. G. Pendleton, and D. L. Decktor, "Antiinflammatory effects of various drugs on acetic acid induced colitis in the rat," Agents and Actions, vol. 30, no. 3-4, pp. 393-402, 1990.

[17] F. Geissmann, S. Jung, and D. R. Littman, "Blood monocytes consist of two principal subsets with distinct migratory properties," Immunity, vol. 19, no. 1, pp. 71-82, 2003. 
[18] C. Sunderkötter, T. Nikolic, M. J. Dillon et al., "Subpopulations of mouse blood monocytes differ in maturation stage and inflammatory response," Journal of Immunology, vol. 172, no. 7, pp. 4410-4417, 2004.

[19] W. A. Kuziel, S. J. Morgan, T. C. Dawson et al., "Severe reduction in leukocyte adhesion and monocyte extravasation in mice deficient in CC chemokine receptor 2," Proceedings of the National Academy of Sciences of the United States of America, vol. 94, no. 22, pp. 12053-12058, 1997.

[20] T. Kurihara, G. Warr, J. Loy, and R. Bravo, "Defects in macrophage recruitment and host defense in mice lacking the CCR2 chemokine receptor," Journal of Experimental Medicine, vol. 186, no. 10, pp. 1757-1762, 1997.

[21] L. Gu, Y. Okada, S. K. Clinton et al., "Absence of monocyte chemoattractant protein-1 reduces atherosclerosis in low density lipoprotein receptor-deficient mice," Molecular Cell, vol. 2, no. 2, pp. 275-281, 1998.

[22] J. Glod, D. Kobiler, M. Noel et al., "Monocytes form a vascular barrier and participate in vessel repair after brain injury," Blood, vol. 107, no. 3, pp. 940-946, 2006.

[23] R. Shechter, A. London, C. Varol et al., "Infiltrating blood-derived macrophages are vital cells playing an antiinflammatory role in recovery from spinal cord injury in mice," PLoS Medicine, vol. 6, no. 7, Article ID e1000113, 2009.

[24] M. Nahrendorf, F. K. Swirski, E. Aikawa et al., "The healing myocardium sequentially mobilizes two monocyte subsets with divergent and complementary functions," Journal of Experimental Medicine, vol. 204, no. 12, pp. 3037-3047, 2007.

[25] R. Mori, T. Kondo, T. Nishie, T. Ohshima, and $M$. Asano, "Impairment of skin wound healing in $\beta-1,4-$ galactosyltransferase-deficient mice with reduced leukocyte recruitment," American Journal of Pathology, vol. 164, no. 4, pp. 1303-1314, 2004.

[26] I. Goren, N. Allmann, N. Yogev et al., "A transgenic mouse model of inducible macrophage depletion: effects of diphtheria toxin-driven lysozyme m-specific cell lineage ablation on wound inflammatory, angiogenic, and contractive processes," American Journal of Pathology, vol. 175, no. 1, pp. 132-147, 2009.

[27] R. Mirza, L. A. DiPietro, and T. J. Koh, "Selective and specific macrophage ablation is detrimental to wound healing in mice," American Journal of Pathology, vol. 175, no. 6, pp. 24542462, 2009.

[28] Y. Ishida, J. L. Gao, and P. M. Murphy, "Chemokine receptor CX3CR1 mediates skin wound healing by promoting macrophage and fibroblast accumulation and function," Journal of Immunology, vol. 180, no. 1, pp. 569-579, 2008.

[29] A. J. Singer and R. A. F. Clark, "Cutaneous wound healing," The New England Journal of Medicine, vol. 341, no. 10, pp. 738 746, 1999.

[30] F. Tacke, F. Ginhoux, C. Jakubzick, N. van Rooijen, M. Merad, and G. J. Randolph, "Immature monocytes acquire antigens from other cells in the bone marrow and present them to $\mathrm{T}$ cells after maturing in the periphery," Journal of Experimental Medicine, vol. 203, no. 3, pp. 583-597, 2006.

[31] U. Yrlid, C. D. Jenkins, and G. G. MacPherson, "Relationships between distinct blood monocyte subsets and migrating intestinal lymph dendritic cells in vivo under steady-state conditions," Journal of Immunology, vol. 176, no. 7, pp. 41554162, 2006.

[32] Y. Zhao, D. Glesne, and E. Huberman, "A human peripheral blood monocyte-derived subset acts as pluripotent stem cells," Proceedings of the National Academy of Sciences of the United States of America, vol. 100, no. 5, pp. 2426-2431, 2003.
[33] J. Crawford, D. K. Tomita, R. Mazanet, J. Glaspy, and H. Ozer, "Reduction of oral mucositis by filgrastim (r-metHuG-CSF) in patients receiving chemotherapy," Cytokines, Cellular and Molecular Therapy, vol. 5, no. 4, pp. 187-193, 1999.

[34] M. Katano, M. Nakamura, T. Matsuo, A. Iyama, and T. Hisatsugu, "Effect of granulocyte colony-stimulating factor (G-CSF) on chemotherapy-induced oral mucositis," Surgery Today, vol. 25, no. 3, pp. 202-206, 1995.

[35] G. J. Lieschke, U. Ramenghi, M. P. O'Connor, W. Sheridan, J. Szer, and G. Morstyn, "Studies of oral neutrophil levels in patients receiving G-CSF after autologous marrow transplantation," British Journal of Haematology, vol. 82, no. 3, pp. 589$595,1992$.

[36] L. Cartee, W. P. Petros, G. L. Rosner et al., "Evaluation of GMCSF mouthwash for prevention of chemotherapy-induced mucositis: a randomized, double-blind, dose-ranging study," Cytokine, vol. 7, no. 5, pp. 471-477, 1995.

[37] H. van der Lelie, B. L. M. Thomas, R. H. J. van Oers et al., "Effect of locally applied GM-CSF on oral mucositis after stem cell transplantation: a prospective placebo-controlled doubleblind study," Annals of Hematology, vol. 80, no. 3, pp. 150-154, 2001.

[38] C. Dazzi, A. Cariello, P. Giovanis et al., "Prophylaxis with GMCSF mouthwashes does not reduce frequency and duration of severe oral mucositis in patients with solid tumors undergoing high-dose chemotherapy with autologous peripheral blood stem cell transplantation rescue: a double blind, randomized, placebo-controlled study," Annals of Oncology, vol. 14, no. 4, pp. 559-563, 2003.

[39] E. M. Ibrahim and F. A. Al-Mulhim, "Effect of granulocytemacrophage colony-stimulating factor on chemotherapyinduced oral mucositis in non-neutropenic cancer patients," Medical Oncology, vol. 14, no. 1, pp. 47-51, 1997.

[40] M. Hejna, W. J. Köstler, M. Raderer et al., "Decrease of duration and symptoms in chemotherapy-induced oral mucositis by topical GM-CSF: results of a prospective randomised trial," European Journal of Cancer, vol. 37, no. 16, pp. 1994-2002, 2001. 


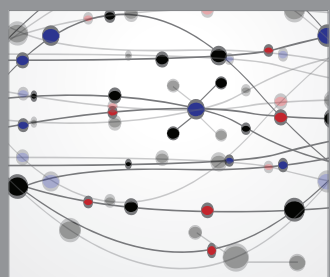

The Scientific World Journal
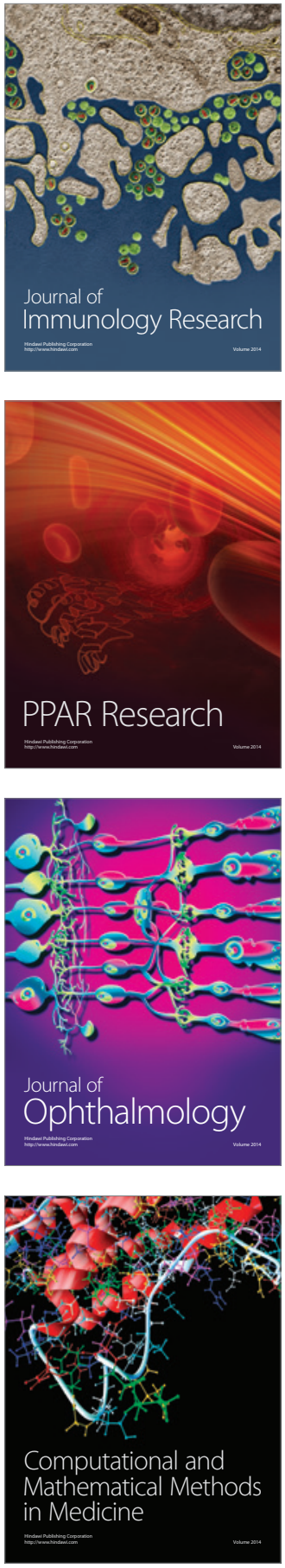

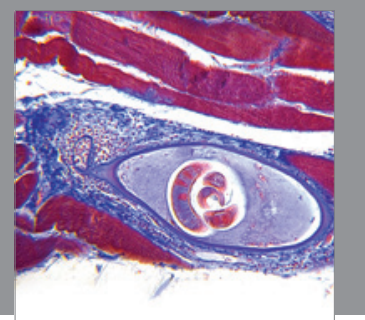

Gastroenterology

Research and Practice
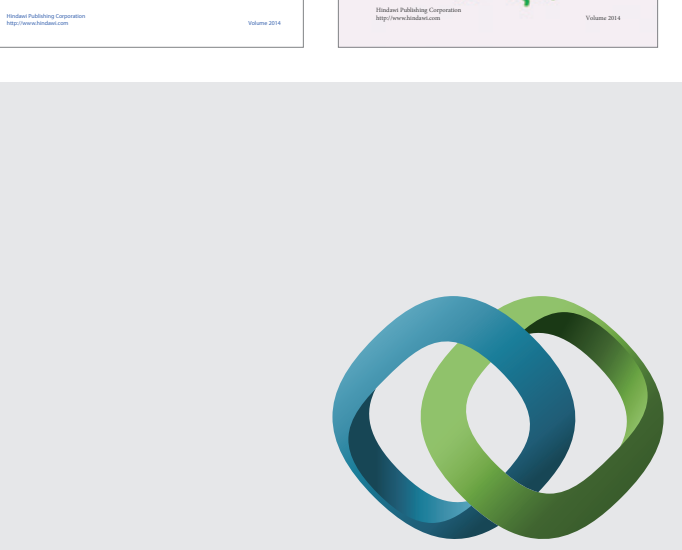

\section{Hindawi}

Submit your manuscripts at

http://www.hindawi.com
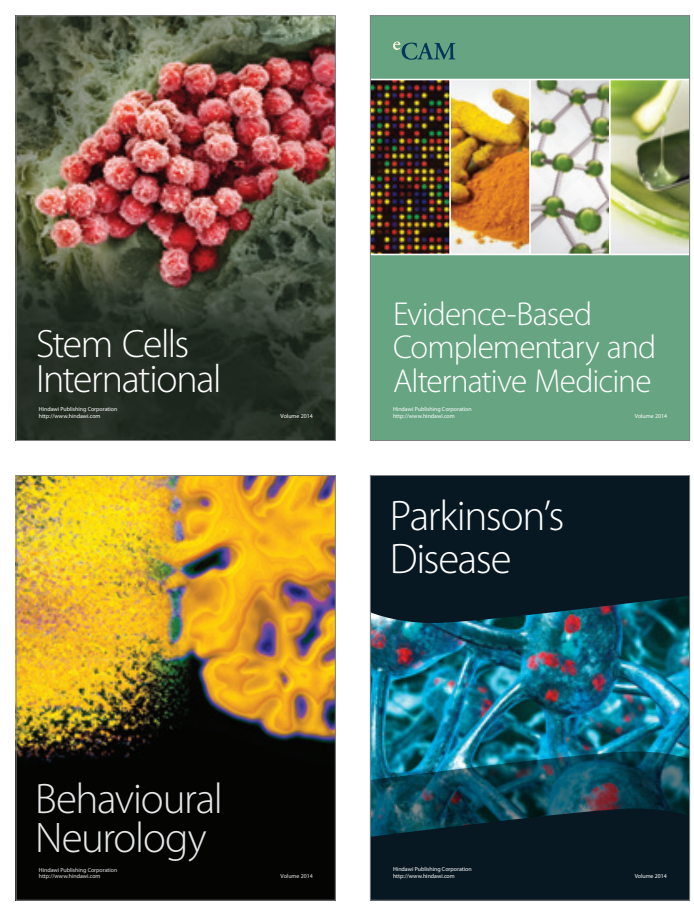

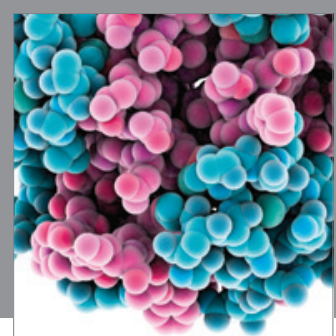

Journal of
Diabetes Research

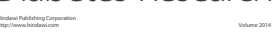

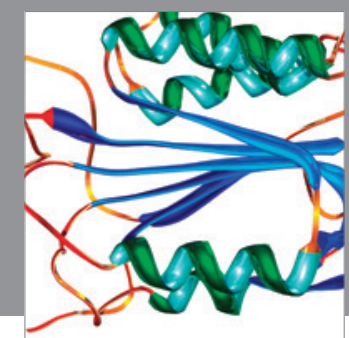

Disease Markers
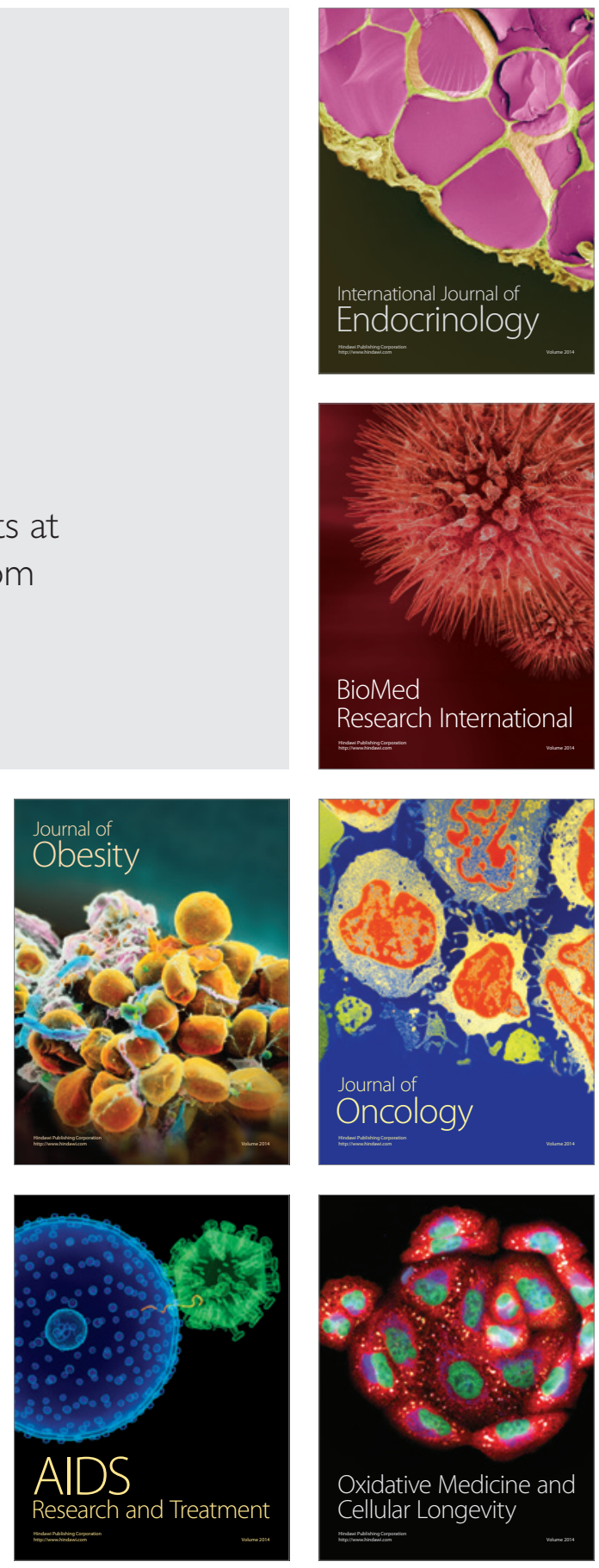